\title{
Endocrine Therapy in Epithelial Ovarian Cancer (EOC) New Insights in an Old Target: A Mini Review
}

\section{Alexandra Knipprath-Meszaros*, Viola Heinzelmann-Schwarz, and Marcus Vetter}

Gynecological Cancer Center, University Hospital Basel, University of Basel, Switzerland

*Corresponding author: Alexandra Knipprath-Meszaros, Gynecological Cancer Center, University Hospital Basel, University of Basel, Switzerland, Tel: +41613287922; Fax: +41612659199; E-mail: alexandra.knipprath@usb.ch

Received date: April 04, 2018; Accepted date: May 09, 2018; Published date: May 15, 2018

Copyright: (02018 Meszaros AK, et al. This is an open-access article distributed under the terms of the Creative Commons Attribution License, which permits unrestricted use, distribution, and reproduction in any medium, provided the original author and source are credited.

\begin{abstract}
Introduction: Endocrine therapy with tamoxifen and aromatase inhibitors has been used in Estrogen Receptor (ER) positive breast cancer for decades. Epithelial ovarian cancer, in particular serous Low- and High Grade Subtypes (LGSOC, HGSOC), shows a similar high ER expression and represents therefore a potential target for endocrine therapy. Many treatments have been evaluated in phase II clinical trials in heavily pretended patients, but the overall tumor response and agent superiority (tamoxifen vs. aromatase inhibitors) remains unclear.
\end{abstract}

Methods: We present a literature review of endocrine therapy for ovarian cancer and emphasize the role of endocrine maintenance therapy with letrozole after standard of care.

Results: Endocrine therapy appears to be an eligible and cost effective treatment option with good quality of life in the adjuvant and recurrent treatment of advanced ovarian cancer. The trend shows the highest effect in histological subtypes with the highest ER expression (LGSOC and HGSOC).

\section{Introduction}

Ovarian cancer is the second most common, and most lethal gynecologic malignancy in developed countries. Worldwide, it accounts for an estimated 239,000 new cases and 152,000 deaths annually [1]. Epithelial Ovarian Cancer (EOC) is the most common histologic type (95\%), with serous being the most common subtype (75\% of epithelial carcinomas, with a further classification into High Grade Serous Cancer (HGSOC) and Low Grade Serous Cancer (LGSOC) [2,3] followed by endometrioid, clear cell and mucinous cancer.

Approximately $65 \%$ of all patients with EOC are diagnosed with stage III or IV disease, which partially explains the poor prognosis (5years-survival 14-23\%). The standard treatment recommendation for advanced disease in all histological subtypes includes optimal cytoreductive surgery followed by a combined chemotherapy with carboplatin and paclitaxel. However, despite high response rates, the prognosis remains poor and most patients will usually relapse within five years of initial diagnosis. There is an urgent need to develop new therapeutic strategies for primary and recurrent disease, as well as for maintenance treatment. To date, angiogenesis-inhibitors and PARPinhibitors are approved for maintenance treatment. However, none of these drugs showed either a significant survival benefit or a better cure rate; therefore, future directions should focus on drugs that improve outcomes by maintaining the best quality of life and extending the length of remission.

Endocrine therapy has been routinely used for decades in adjuvant and recurrent breast cancer with a high efficacy at low costs. In the adjuvant setting aromatase inhibitors reduces the risk of recurrence by 40-50\%. Evidence of the stimulating effect of estrogen and progesterone on ovarian cancer progression and metastasis has been demonstrated in previous studies [4] and the use of endocrine treatment in ovarian cancer has been evaluated in several clinical phase I and II studies.

\section{Methods}

We did a comprehensive literature review including all phase I, II and III trials as well as meta-analysis and previous reviews related to endocrine treatment in ovarian cancer through computerized and manual searches.

\section{Results}

\section{Estrogen and progesterone expression in ovarian cancer}

Similar to breast cancer, the majority of ovarian carcinomas express estrogen receptors [5]. In a recent publication, we could demonstrate similarly high expression of ESR1 in ovarian and breast cancer and a strong ER expression in both primary and matched recurrent HGSOC, particularly in the platinum-resistant subgroup [6]. Estrogen is known to drive disease in ER positive breast cancer patients. Several preclinical models have demonstrated the role of estrogen in terms of tumor proliferation and progression in EOC through direct (tumor VEGF production via ER signaling) and indirect (increased cell migration via protein kinase signaling) pathways $[4,7]$.

In one of the largest consortia studies by Sieh et.al [8] including more than 2,900 primary ovarian cancer samples, the expression rate of ER varied between $20-90 \%$, depending on the ovarian cancer subtype: low-grade serous ovarian cancer $87 \%$, high-grade serous ovarian cancer $81 \%$, mucinous ovarian cancer $21 \%$, endometrioid ovarian cancer $76 \%$ and clear cell ovarian cancer $20 \%$ [8]. In highgrade serous cancers, a strong PR expression was associated with a significant better survival compared to lower PR expression. In 
contrast, higher ER expression was not associated with significant better survival outcome. In a Chinese meta-analysis with more than 6,000 patients, higher ER expression was also not prognostic, in contrast to PR and HER2 expression [9].

\section{Benefits of endocrine therapy in ovarian cancer}

Since 1982, more than 50 trials evaluated the efficacy of endocrine therapy in ovarian cancer, but no controlled randomised studies have been reported to date. Almost all trials included patients with prior treatments. Overall, studies lack standardised analyses with inconstancy in the use of endocrine agent (mostly used: tamoxifen, letrozole, anastrozole, exemestane), poorly defined histological subtypes and ER expression as well as unclear prior therapeutic treatment, which may explain the inconstancy of the results. Positive hormonal receptor status (ER/PR) and histologic subtype seems to be of relevance when it comes to response to endocrine therapy [10-12]. Recently, in a meta-analysis involving 2490 patients, Paleari et al. $[13,14]$ found a clinical benefit rate of $41 \%$ in EOC patients with endocrine therapy, suggesting that there are subgroup of patients with tumor biology that responds very well to treatment. Tamoxifen showed the highest clinical benefit rate (CBR) (43\%) based on 23 studies, while the CBR for aromatase inhibitors in 10 studies was 39\% [13].
Tamoxifen: Tamoxifen is a selective estrogen receptor blocker and its utility and safety have largely been proven in breast cancer. The first to describe its effect on ovarian cancer was Myers in 1981, and several Phase II studies have followed, listed in (Table 1) [14]. A meta-analysis demonstrated an objective response rate of 9.6\% (60 out of 623 patients) with a variation between $0-56 \%$ and a clinical benefit rate of $32 \%$, ranging from $0-100 \%$. Stable disease for more than four weeks, was observed in 131 of 411 (31.9\%) women. In 2010 the author updated the meta-analysis but was not able to give any evidence-based recommendations. An important note is that most of the patients in the mentioned trials were heavily pretreated and the ER status was not established, making a clear statement about the clinical benefit difficult. In a systematic review, Perez-Gracia et al. [15] found a response rate of $13 \%$ in a total of 648 patients while the stabilization rate was $38 \%$ [15]. A low response rate to tamoxifen was directly associated with the number of prior treatment: A response rate of $26 \%$ could be found when selecting the trials where most patients received no more than one prior therapy, whereas heavily pretreated patients showed a response rate of only $4 \%$.

\begin{tabular}{|c|c|c|c|c|}
\hline Study/year/country & $\begin{array}{l}\text { No. of pts/no. } \\
\text { of evaluable pts }\end{array}$ & Daily dose (mg) & $\begin{array}{l}\text { CBR } \\
\text { N (\%) }\end{array}$ & Refractory/resistant to platinum \\
\hline Schwartz PE, 1982, USA & $13 / 13$ & 20 & $5(38.4)$ & Yes \\
\hline Schwartz PE, 1989, USA & $49 / 49$ & 20 & NR & No \\
\hline Pagel J, 1983, Denmark & $29 / 21$ & 20 & $20(95.2)$ & No \\
\hline Shirey DR, 1985, USA & $23 / 23$ & 20 (11 pts) 40 (12 pts) & 19 (82.6) & Yes \\
\hline Rowland K, 1985, USA & $9 / 9$ & 40 & $0(0)$ & NR \\
\hline Hamerlynck JVTH, 1985, Netherlands & $64 / 18$ & 40 & $0(0)$ & Yes \\
\hline Landoni F, 1985, Italy & $63 / 55$ & 40 & $19(34.5)$ & No \\
\hline Campbell JJ, 1985, Australia & $22 / 22$ & 40 & $12(54.5)$ & Yes \\
\hline Slevin ML, 1986, UK & $22 / 22$ & 40 & $1(4.5)$ & Mixed \\
\hline Weiner SA, 1987, USA & $37 / 31$ & 20 & $9(29)$ & NR \\
\hline Quinn MA, 1987, Australia & $40 / 40$ & 40 & $21(52.5)$ & NR \\
\hline Osborne RJ, 1988, UK & $53 / 51$ & 40 & $1(1.9)$ & Yes \\
\hline Hatch KD, 1991, USA & $105 / 105$ & 40 & $58(55.2)$ & NR \\
\hline Ahlgren JD, 1993, USA & $29 / 29$ & 80 (days $1-30$ ) then 40 & $23(79.3)$ & Mixed \\
\hline Losa G, 1993, Italy & $55 / 55$ & 40 & $23(41.8)$ & NR \\
\hline Jager W, 1995, Germany & $37 / 33$ & 30 & $23(69.7)$ & Yes \\
\hline van der Vange N, 1995, Netherlands & $10 / 6$ & 40 & $2(33.3)$ & Yes \\
\hline van der Velden J, 1995, Australia & $30 / 30$ & 40 & $12(40)$ & NR \\
\hline Gennatas C, 1996, Greece & $50 / 50$ & 40 & $28(56)$ & Mixed \\
\hline Marth C, 1997, Norway & $155 / 65$ & 30 or 40 & $54(83)$ & Yes \\
\hline Rolski J, 1998, Poland & $47 / 47$ & 40 & $25(53.2)$ & NR \\
\hline
\end{tabular}


Citation: Meszaros AK, Schwarz VH, Vetter M (2018) Endocrine Therapy in Epithelial Ovarian Cancer (EOC) New Insights in an Old Target: A

Page 3 of 5

\begin{tabular}{|l|l|l|l|l|}
\hline Trope C, 2000 & $66 / 55$ & 30 or 40 & $55(100)$ & NR \\
\hline Benedetti Panici P, 2001, Italy & $28 / 28^{\#}$ & 80 (days 1-30) then 40 & $19(67.8)$ & Yes \\
\hline & $22 / 226$ & 80 (days 1-30) then 40 & $18(81.8)$ & No \\
\hline Markman M, 2004, USA & $14 / 14$ & 80 for 1 month then 40 & $0(0 \%)$ & Yes \\
\hline Wagner U, 2007, Germany & $56 / 56$ & 40 & $16(28.6)$ & Yes \\
\hline Harteau JA, 2010, USA & $70 / 70$ & 40 & $5(7.1)$ & Mixed \\
\hline George A, 2017, UK & $43 / 43$ & 20 (36 Pts) 40 (7 pts) & $28(65.1)$ & Mixed \\
\hline CBR, clinical benefit rate (CR + PR + SD), \#Platinum-sensitive population, 'Platinum-resistant population. & \\
\hline
\end{tabular}

Table 1: Clinical trials of tamoxifen in recurrent ovarian cancer.

Therefore, unselective treatment in the whole population of patients with EOC may underestimate the actual efficacy of endocrine treatment. In one of the largest tamoxifen trials with 105 patients, almost all patients with complete response had elevated Estrogen Receptors (ER) (89\%). In contrast, only 59\% had elevated ER when patients had low or non ER [16]. In a publication by Swartz et al., all patients with stable disease had ER positive tumors [17]. In this study, the role of concurrently given tamoxifen with chemotherapy was evaluated but no difference in Progression Free Survival (PFS) and Overall Survival (OS) was shown between patients on tamoxifen and those not receiving tamoxifen. One weakness of this study was that tamoxifen was administrated for only 36 weeks. As mentioned, the latest meta-analysis published in 2017 reported an overall clinical benefit rate for tamoxifen of $43 \%$ in 53 trials examined.
Aromatase inhibitors (AI): Aromatase inhibitors reduce the conversion of androgens to estrogens by about $90 \%$ and are the key enzymes of in-situ estrogen metabolism in postmenopausal women. Its expression in ovarian cancer ranges from $33 \%$ to $81 \%$ [18]. The use of Aromatase Inhibitors (AI's) in ovarian cancer has been reported since the 1990's with a clinical benefit rate ranging from 20-65\% (Table 2) [14]. Most recently, combined therapy with letrozole and the mTOR inhibitor everolimus in recurrent ER positive HGSOC showed a promising 12-week PFS rate of $47 \%$ [19]. A study by Bowman et al. showed that a high degree of ER expression was predictive of tumor marker CA125 responses and stabilization of disease [20]. Smyth had similar findings, enhancing the evidence that the degree of ER expression correlates with the response to endocrine treatment [21].

\begin{tabular}{|l|l|l|l|l|l|}
\hline Study/Year/Country & No. of Pts/ No. of evaluable pts & Agent & Daily dose $(\mathbf{m g})$ & CBRN(\%) & Refractory/ Resistant to platinum \\
\hline Ahlgren JD, 1993, USA & $15 / 15$ & Aminoglutethimide & 1000 & $3(20)$ & Mixed \\
\hline Bowman A, 2002, UK & $60 / 54$ & Letrozole & 2.5 & $19(35.2)$ & NR \\
\cline { 2 - 6 } & $60 / 50$ & Letrozole & 2.5 & $10(20)$ & NR \\
\hline del Carmen MG, 2003, USA & $53 / 53$ & Anastrozole & 1 & $23(43.4)$ & No \\
\hline Papadimitriou CA, 2004, Greece & $27 / 27$ & Letrozole & 2.5 & $9(33.4)$ & Yes \\
\cline { 2 - 6 } & $27 / 21$ & Letrozole & 2.5 & $7(33.4)$ & Yes \\
\hline Krasner CN, 2005, USA & $35 / 23$ & Anastrozole & 1 & $15(65.2)$ & NR \\
\hline Verma S, 2006, Canada & $24 / 22$ & Exemestane & 25 & $9(41)$ & Yes \\
\hline Tchekmedyian AK, 2006, USA & $14 / 14$ & Letrozole & 2.5 & $10(71.4)$ & NR \\
\hline Kavanagh JJ, 2007, USA & $13 / 13$ & Letrozole & 2.5 & $9(69.3)$ & NR \\
\cline { 2 - 6 } & $13 / 13$ & Letrozole & 2.5 & $5(38.5)$ & NR \\
\hline Smyth JF, 2007, UK & $44 / 42$ & Letrozole & 2.5 & $18(42.8)$ & Mixed \\
\hline & $44 / 42$ & Letrozole & 2.5 & $17(40.5)$ & Mixed \\
\hline Ramirez PT, 2008, USA & $33 / 31$ & Letrozole & 2.5 & $8(25.8)$ & Yes \\
\hline George A, 2017, UK & $54 / 54$ & Letrozole & 2.5 & $30(55.6)$ & Mixed \\
\hline
\end{tabular}




\begin{tabular}{|l|l|l|l|l|l|}
\hline Colon-Otero G, 2017, USA & $20 / 19$ & Letrozole & 2.5 & NR & Mixed \\
\hline
\end{tabular}

Table 2: Clinical trials of aromatase inhibitors in recurrent ovarian cancer.

Use of AI in LGOSC and HGSOC: Because of its high ER expression, low and high grade ovarian cancer subtype could particularly benefit from endocrine treatment. In a study on advanced LGSOC, Gershenson retrospectively analyzed 64 patients treated with letrozole, anastrazole and tamoxifen in recurrent EOC and showed an overall response rate of $9 \%$, while $61 \%$ of the patient had a PFS of 6 months or greater, independent of the anti-hormonal agents [22]. Four years later, the same author analyzed the effect of hormonal maintenance therapy vs. surveillance in LGSOC after completion of primary therapy and found a significant benefit in the PFS with hormonal therapy (64.9 months vs 26.4 for matched surveillance patients $(p=0.001)$ [23]. Most patients received treatment with letrozole $(54 \%)$ followed by tamoxifen $(28 \%)$. In a previous study, we could demonstrate the utility of letrozole for maintenance treatment following first line therapy with cytoreductive surgery and platinumbased chemotherapy in high grade ovarian cancer [6]. Patients treated with letrozole showed significantly prolonged recurrence free intervals in comparison to the control group. After 24 months, $60 \%$ of patients were progression free while taking letrozole vs. $38.5 \%$ in the control group; $\mathrm{p}=0.035$ ). This effect was also present in patients treated additionally with Bevacizumab; $20.8 \%$ of patients had no recurrence after 12 months compared to $87.5 \%$ when taking letrozole in addition to Bevacizumab $(\mathrm{p}=0.026)$. The biggest effect was shown when letrozole was initiated in parallel to first line chemotherapy and the effect was similar in patients showing chemoresistance. The effect of endocrine therapy in platinum-resistant or refractory recurrent ovarian cancer has been demonstrated in the Paragon-Study, with a clinical benefit in $27 \%$ of the patients taking anastrozole [24]. The authors also demonstrated an improvement of quality of life in patients under this treatment.

\section{Summary}

The promising results of endocrine therapy in ovarian cancer with a clinical benefit up to $41 \%$, in combination with the low cost and toxicity of the drug, offer a new and cost-effective therapeutic option in the adjuvant and recurrent setting. When selecting ER positive cancers, the effect seems to be even higher. These findings justify a routine determination of ER-status for all newly diagnosed ovarian cancers and, when positive, the initiation of endocrine treatment in the adjuvant and recurrent setting. This could significantly delay the time to next treatment and improve the quality of life.

\section{References}

1. Ferlay J, Soerjomataram I, Ervik M, Dikshit R, Eser S, et al. (2013) Globocan 2012 v1.0, Cancer Incidence and Mortality Worldwide: IARC CancerBase No. 11, International Agency for Research on Cancer, Lyon, France.

2. Lacey JV, Sherman ME (2009) Ovarian neoplasia. In: Robboy SL, editors. Robboy's Pathology of the Female Reproductive Tract. Churchill Livingstone Elsevier: Oxford; 2009. p. 601.

3. Ben-Baruch G, Sivan E, Moran O, Rizel S, Menczer J, et al. (1996) Primary peritoneal serous papillary carcinoma: a study of 25 cases and comparison with stage III-IV ovarian papillary serous carcinoma. Gynecol Oncol 60: 393-396.
4. Matsuo K, Sheridan TB, Mabuchi S, Yoshino K, Hasegawa K, et al. (2014) Estrogen receptor expression and increased risk of lymphovascular space invasion in high-grade serous ovarian carcinoma. Gynecol Oncol 133: 473-479.

5. Rao BR, Slotman BJ (1991) Endocrine factors in common epithelial ovarian cancer. Endocr Rev 12: 14-26.

6. Heinzelmann-Schwarz V, Mészaros AK, Stadlmann S, Jacob F, Schoetzau A, et al. (2018) Letrozole may be a valuable maintenance treatment in highgrade serous ovarian cancer atients. Gynecol Oncol 148: 79-85.

7. Langdon SP, Hirst GL, Miller EP, Hawkins RA, Tesdale AL, et al. (1994) The regulation of growth and protein expression by estrogen in vitro: a study of 8 human ovarian carcinoma cell lines. J Steroid Biochem Mol Biol 50: 131-135.

8. Sieh W, Kobel M, Longacre TA, Bowtell DD, deFazio A, et al. (2013) Hormone-receptor expression and ovarian cancer survival: an ovarian tumor tissue analysis consortium study. Lancet Oncol 14: 853-862.

9. Zhao D, Zhang F, Zhang W, He J, Zhao Y, et al. (2013) Prognostic role of hormone receptors in ovarian cancer: a systematic review and metaanalysis. Int J Gynecol Cancer 23: 25-33.

10. Langdon SP, Crew AJ, Ritchie AA, Muir M, Wakeling A, et al. (1994) Growth inhibition of oestrogen receptor-positive human ovarian carcinoma by anti-oestrogens in vitro and in vivo. Eur J Cancer 30: 682-686.

11. O’Donnell AJM, MacLeod KG, Burns DJ, Smyth JF, Langdon SP (2005) Estrogen receptor mediates gene expression changes and growth response in ovarian cancer cells exposed to estrogen. Endo Rel Cancer 12: 851-866.

12. Gourley C (2013) Hormone receptors and ovarian cancer survival. Lancet Oncol 14: 794-795.

13. Paleari L, Gandini S, Provinciali N, Puntoni M, Colombo N, et al. (2017) Clinical benefit and risk of death with endocrine therapy in ovarian cancer: a comprehensive review and metaanalysis. Gynecol Oncol 146: 504-513.

14. Paleari L, DeCensi A (2018) Endocrine therapy in ovarian cancer: where do we stand? Curr Opin Obstet Gynecol 30:17-22.

15. Perez-Gracia JL, Carrasco EM (2002) Tamoxifen therapy for ovarian cancer in the adjuvant and advanced settings: systematic review of the literature and implications for future research. Gynecol Oncol 84: 201-209.

16. Hatch KD, Beecham JB, Blessing JA, Creasman WT (1991) Responsiveness of patients with advanced ovarian carcinoma to tamoxifen. Cancer 68: 269-271.

17. Schwartz PE, Chambers JT, Kohorn EI, Chambers SK, Weitzman H, et al. (1989) Tamoxifen in combination with cytotoxic chemotherapy in advanced epithelial ovarian cancer. A prospective randomized trial. Cancer 63: 10740-1078.

18. Cunat S, Rabenoelina F, Daurès JP, Katsaros D, Sasano H, et al. (2005) Aromatase expression in ovarian epithelial cancers. J Steroid Biochem Mol Biol 93:15-24.

19. Colon-Otero G, Weroha SJ, Foster NR, Haluska P, Hou X, et al. (2017) Phase 2 trial of everolimus and letrozole in relapsed estrogen receptorpositive high-grade ovarian cancer. Gynecol Oncol 146: 64-68.

20. Bowman A, Gabra H, Langdon SP, Lessells A, Stewart M, et al. (2002) CA125 response is associated with estrogen receptor expression in a phase II trial of letrozole in ovarian cancer: identification of an endocrine-sensitive group. Clin Cancer Res 8: 2233-2239.

21. Smyth JF, Gourley C, Walker G, MacKean MJ, Stevenson A, et al. (2007) Antiestrogen therapy is active in selected ovarian cancer cases: the use of letrozole in estrogen receptor positive patients. Clin Cancer Res 13: 3617-3622. 
Citation: Meszaros AK, Schwarz VH, Vetter M (2018) Endocrine Therapy in Epithelial Ovarian Cancer (EOC) New Insights in an Old Target: A Mini Review. J Cancer Clin Trials 3: 144. doi:10.4172/2577-0535.1000144

Page 5 of 5

22. Gershenson DM, Sun CC, Iyer RB, Malpica AL, Kavanagh JJ, et al. (2012) Hormonal therapy for recurrent low-grade serous carcinoma of the ovary or peritoneum. Gynecol Oncol 125: 661-666.

23. Gershenson DM, Bodurka DC, Coleman RL, Lu KH, Malpica A, et al. (2017) Hormonal maintenance therapy for women with low-grade serous cancer of the ovary or peritoneum. J Clin Oncol 35: 1103-1111.
24. Bonaventura A, O'Connell RL, Mapagu C, Beale PJ, McNally OM, et al. (2017) Paragon InvestigatorsParagon (ANZGOG-0903): Phase 2 Study of Anastrozole in Women With Estrogen or Progesterone Receptor-Positive Platinum-Resistant or -Refractory Recurrent Ovarian Cancer. Int J Gynecol Cancer. 27: 900-906. 